\title{
EMERGING TRENDS OF TROPICAL RESIDENTIAL BUILDINGS IN THE PACIFIC-RIM REGION IN THE AGE OF GLOBALIZATION: BASED ON CASE ANALYSIS IN CHINA, COSTA RICA AND AUSTRALIA
}

\author{
ZEYANG YU \\ School of Architecture and Urban planning, Huazhong University of Science and Technology, China
}

\begin{abstract}
This paper attempts to discover the changes of tropical residential buildings in the pacific-rim region under the globalization, to find the emerging trends which this kind of building can follow. The trends can be identified through case studies in China, Costa Rica and Australia by comparing the traditional and modern tropical residential buildings and analysing the authenticity of them. The emerging trends include the relationship with the natural environment, the local identity and personal experience. The paper consists of three parts. The first and second part analyses the characteristics of traditional and modern tropical residential buildings. The third part compares these characteristics, thus summarizing the changes and identifying which parts can be represented as trends.

Keywords: tradition, modernity, tropical architecture, globalization, emerging trends.
\end{abstract}

\section{INTRODUCTION}

Tropical residential buildings are a branch of architecture. The basic function of them is for the shelter of human beings [1]. From the geographical perspective, the forms and the main material of it are different across the regions as the effect of local environment which include: climate, topography, nature resource and culture. From the perspective of time, tropical residential building mainly used local material before the $20^{\text {th }}$ century because of the limitation of transportation [2]. Nowadays, the limitation disappeared with the development of science and technology and the characteristics of this kind of building keep changing with the rapid process of globalization. Therefore, the essences and the forms, which should be kept and developed, of the contemporary tropical residential building should be considered.

Due to this situation, the paper committed to discovering the differences between the traditional tropical residential building which was built before the $20^{\text {th }}$ century and the modern ones which is under the influence of globalization. Furthermore, analysis these differences and clarify the essence of tropical residential building which should be considered as the emerging trends. There have three parts are focused which include: material, structure and the identity which reflect the local culture.

\section{TRADITIONAL TROPICAL RESIDENTIAL BUILDING}

A pervasive stereotyping of the traditional tropical residential building has four features: wood structure, sloping roof, deep eaves and sun-shading louver. But it is one form of this kind of building, there also have many other forms exist. The variety of regional resources creates the diversity of traditional tropical residential building.

In Hainan, which is the second largest island in south of China, the indigenous people have lived there for hundreds of years. The main kind of traditional residential building is called Ship-type house (Fig. 1). As the forest is the mainly natural resource, the trunk and bamboo are used as the beams and columns of buildings, the branches paly as connections between columns and roofs, the dried grass are used to cover the roofs. 




Figure 1: Outside the Ship-type house, Hainan, China.

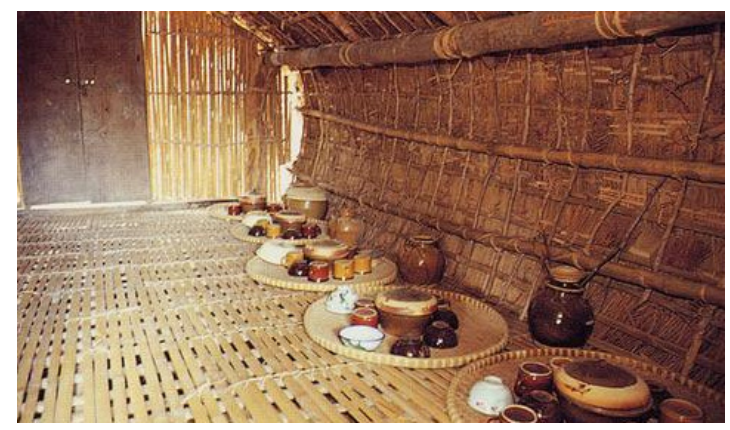

Figure 2: Inside the Ship-type house, Hainan, China.

The main feature of its structure is that the roof and wall work as one body (Fig. 2). The connections between components use rattan to tight together. Therefore, all components in the structure are connected which can enhance the stability of houses and resist the typhoon [3]. The shape is similar as an arch which represents the local culture. As the ancestors of these indigenous people came from mainland, ship is the main transportation means to connect two sides. Therefore, in order to commemorate the ancestors, they took the shape of ship as the form of their buildings.

In Costa Rica, which is twice as big as Hainan island, leaves and wood are the main material in their buildings. Leaves are tight together as roofs and wood stakes play as walls. As the feature of wood stake is irregular and high, the internal space of the building is quite large and wind can through into it. A large interior space with a long cornice would be considered as the characteristics of this kind of building at the time that before this mainland was discovered by Europe. In colonial period, the Europe brought new technologies and materials. The adobe is one of them. It is used to replace the leaves and wood as the main material of buildings. Compare with the former kind building, this one has changed in many parts. For instance, there only have few openings on the wall which block the visual connection with surrounding environment. But in the building, there have a courtyard which can introduce the natural light and promote ventilation [4]. The main concerns of these two 
kinds of buildings are different. One is tending to get the connection between inside and outside. The other is seems to isolate the building. These changes can be thought as the representations of different cultures.

In the North Territory, which is located in north of Australia, the existing traditional residential buildings were mainly built during the colonial period, therefore, they can be thought as reflections of British culture. The main material of these buildings is wood. They usually have steep pitched roofs and open eaves to catch the wind (Fig. 3).

According to the weather conditions, the internal space could be adjusted by louvers. The rooms are separated, but on the top of the wall there have space left for cross-ventilation (Fig. 4) [5]. Compare with the traditional tropical architectures which located in Hainan and Costa Rica, these buildings are more intelligent as they can modify the internal environment by louvers.

Through the cases analysis in these three countries, the key elements of the traditional tropical residential building can be found: the slopping roof which is designed to satisfy the requirement of drainage. The long cornice which is set to played as a sunshade to avoid the sunlight through into the interior directly. The ventilate opening which is used to promote the air exchange and dehumidification. All the key elements run through stages of the development of traditional tropical residential building.

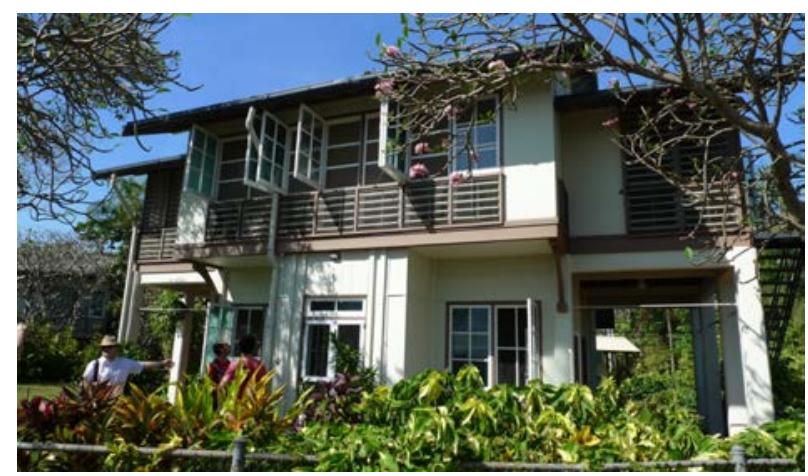

Figure 3: Burnett House outside, Darwin, Australia.

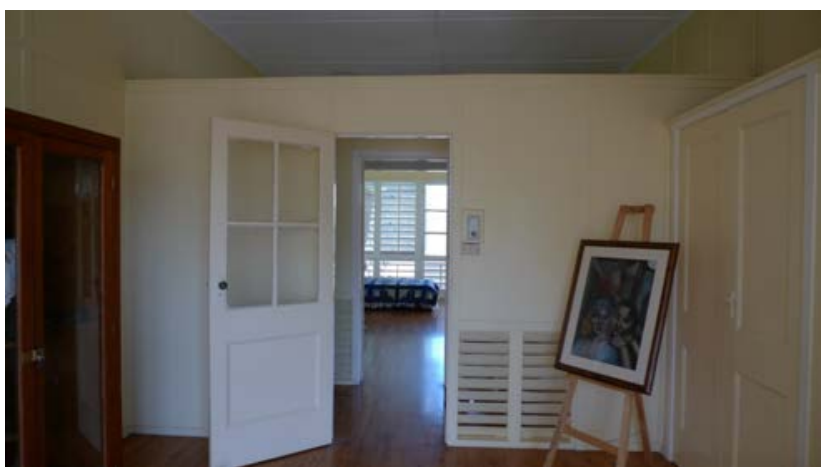

Figure 4: Burnett House inside, Darwin, Australia. 
3 MODERN TROPICAL RESIDENTIAL BUILDING IN GLOBALIZATION

The study of modern tropical residential building should be divided into two periods. One is the first half of the $20^{\text {th }}$ century, the other is the second half of the $20^{\text {th }}$ century.

At the beginning of the $20^{\text {th }}$ century, the movement of modernism sweeps the whole world. It also has influenced the tropical residential building [4]. The modernism has introduced some new ideas and concepts into the design of this kind of building, for instance, an open space with concise façade, a reinforced- concrete structure with a dynamic building style. As the material, structure and form have changed, compare with the traditional tropical architecture, the modern ones might be more attractive. Therefore, tradition and modernity are usually thought on opposite sides at that time. The former one would be related to stagnation and regression, the latter one should be thought as progress [4]. New material with advanced technology is the key element of tropical residential building in that period.

There have two styles of tropical residential building in that period. One is traditional style which prefers use tradition building languages to represent the culture, but they do not use the same material which was adopted in real traditional tropical architecture. They choose to use polymer material to make the fake structure which is similar like the long cornice or the complex structure with decorations. They take artificial material to achieve the effect of natural ones. At the end, this kind of building is meaningless. It is only an imitation of traditional tropical architecture. The other is modern style which focuses on the new material and structure with high technology. However, this kind of building is only workable in developed countries which have enough financial resources to support it. Developing countries cannot afford the high cost and hard to meet the requirement of new technology at that period [1].

Fortunately, with the development of society, this situation has changed in the second half of the $20^{\text {th }}$ century. There have some new concepts which start thinking respect the environment and recover the feature of traditional culture in recent years [6]. These new architectures excavate the essences of traditional building language and express them in a modern way. This paper chooses three buildings as examples to analysis the new concepts.

The villa fifth: located in Shenzhen, China. It is a residential area. The concept of this project is bases on the traditional tropical architecture. The design refining the traditional village architectural forms and expresses them in a modern way. In order to get more connections with environment, the plan is integrated by many open spaces such as outdoor corridor, terrace and courtyard. Free layout creates an interesting internal space (Fig. 5).

Many essences of the traditional tropical architecture have been used on the façade design, such as the slopping roof with long cornice, timber sun-shade and large terrace. All of them have real functions and not only used for decoration (Fig. 6). The long cornice avoid the sunlight through into the interior directly while make sure there have enough light in interior. Large terrace which use as open space provide more opportunities for people to connect with nature. For the material, they choose tiles, wood and shale which are produce from local. The texture of these materials express the original beauty of nature and similar as the traditional tropical architecture. All of these things express the features of tropical architecture in an appropriate way.

Casa Atrevida: located in Osa Peninsula, Costa Rica. This is a two-storey villa with open space layout (Fig. 7). In order to follow the concept of sustainability and keep harmony with environment, the architect use the local bamboo as the main material in the structure, set the solar photovoltaic to provide electricity and hot water for the building. The whole building built above the ground to stay away from damp and flood. 

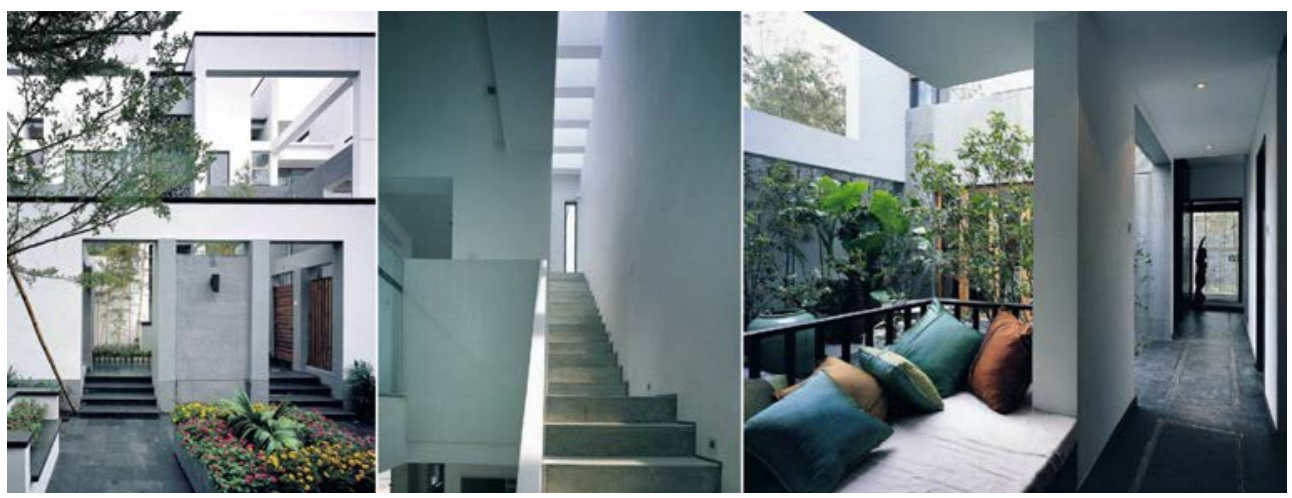

Figure 5: The internal space of Vanke 5th Garden, Shenzhen, China.



Figure 6: The public building of Vanke 5th Garden, Shenzhen, China.

The indoor temperature is mainly regulated by natural ventilation and electric fan. All of them are simplified modernist forms while express the characteristics of tropical architecture. Compare with the first example, it is more obviously to see how a building uses a modern way to express the essences of traditional tropical architecture.

House X (name unknown): located in suburb of Darwin, Australia. The form of this building is similar like the traditional tropical architecture in Darwin. Steep pitched roofs, open eaves, louvers which use to adjust the temperature of interior, large internal space with enough natural light, good ventilation as all the rooms are connected with outside (Figs 8 and 9). The different part is the structure, it mainly uses steel as it structure. Wood, metal and glass cooperate with each other. In order to protect the building from moisture, the whole ground floor is elevated. It would also be good for the modification of indoor temperature as the wind can flow under the floor. This is simple project with new idea that combines the essences of traditional tropical architecture with new material and structure. 

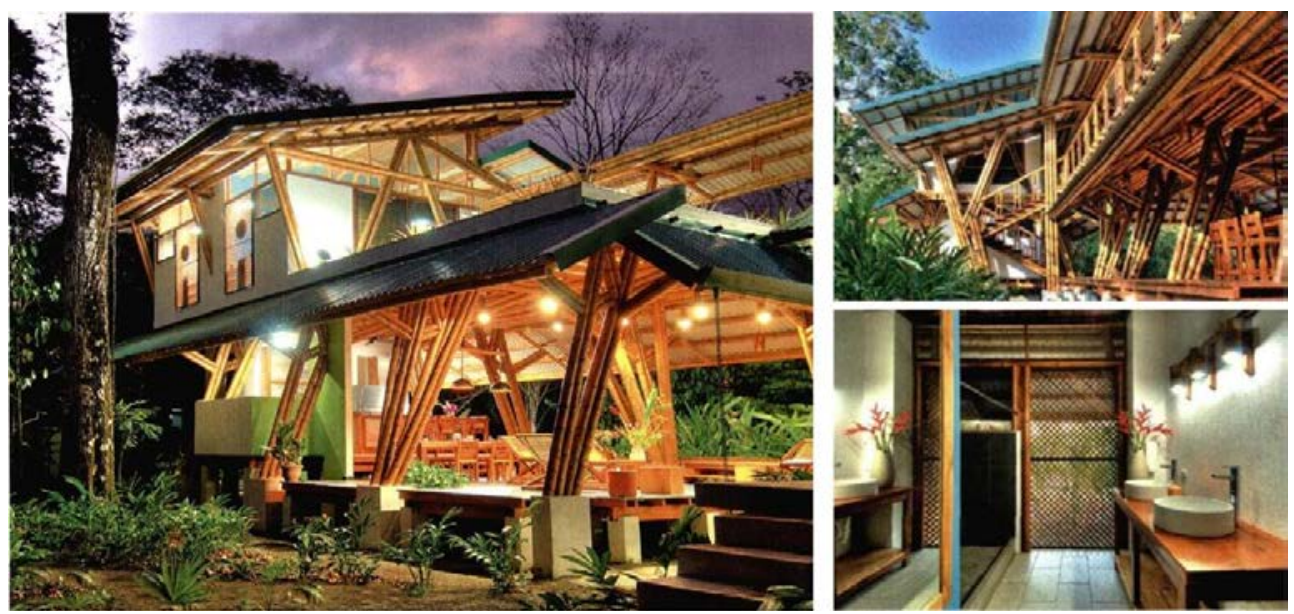

Figure 7: Casa Atrevida, Osa Peninsula, Costa Rica.



Figure 8: House X outside, Darwin, Australia.

From these practices, the spirit of modern tropical residential building can be considered as combine the tradition with the characteristics of different regions. In the process of globalization, there will have more and more new tropical residential building which is similar like these examples. They would have these features: respect to nature environment, represent the characteristics of regions, new material with low consumption. 


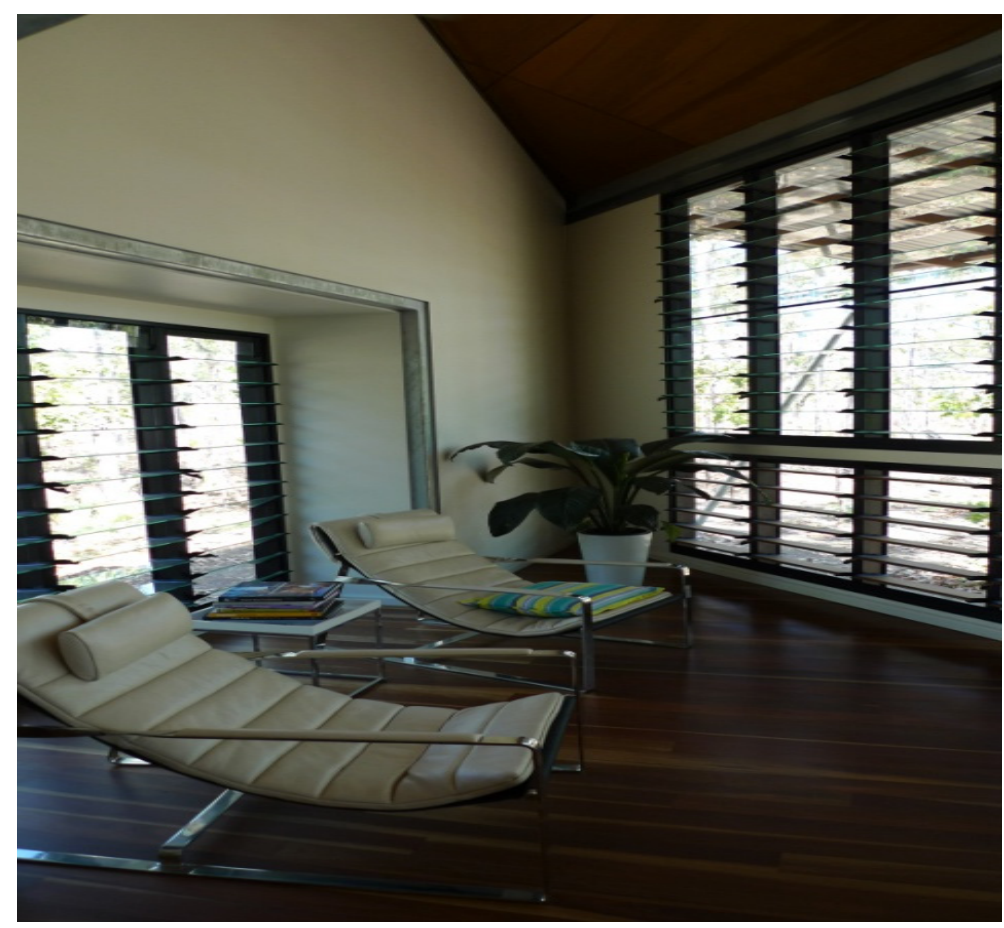

Figure 9: House X inside, Darwin, Australia.

Table 1: The characteristic of traditional tropical residential building and modern tropical residential building.

\begin{tabular}{|c|c|c|c|}
\hline Style & Material & Structure & Identity \\
\hline Tradition & Wood/Adobe & Timber/Brick-timber & Local culture \\
\hline $\begin{array}{c}\text { Modernity (the first half } \\
\text { of the } 20^{\text {th }} \text { century) }\end{array}$ & Concrete & Brick-concrete & Meaningless \\
\hline $\begin{array}{c}\text { Modernity (the second } \\
\text { half of the } 20^{\text {th }} \text { century) }\end{array}$ & $\begin{array}{c}\text { Wood/Steel/ } \\
\text { Concrete }\end{array}$ & $\begin{array}{c}\text { Timber/Steel/Reinforced } \\
\text { concrete }\end{array}$ & Local culture \\
\hline
\end{tabular}

4 THE EMERGING TRENDS OF TROPICAL RESIDENTIAL BUILDING

Compare these two styles of tropical residential building, the change mainly happens on the material, structure and the identity of the building. The material of the building keeps changing with the change of times. The structure changed with the development of science and technology. The identity of the building is also affected by the society transformation (Table 1).

Most of the factors might keep changing with the development of society. But one factor is stable. That is the relationship with nature. It is the most stable influencing factor and never be affected by different culture or regional tradition. As Alvar Aalto said, architecture can never exist without nature and human, on contrary, it should make the human has a closer 
relationship with nature [7]. Therefore, how to develop the relationship between tropical residential building and the natural environment would be one direction.

The other one, as a global society, the tropical residential building has come into a new stage. This stage is not only focused on image which the building tends to express but will pay more attention on kind of emotion and experience they can have [4]. With interpenetration between different regions' tradition and culture, the characteristics of local area are not clear as before. The new architecture should have the power that endows the different cultures in the world with distinct character. The way that expresses the local distinct character would be the other one direction that the tropical residential building should develop.

The third one: memory. A scientist has recorded some psychological phenomena which relate to memory that can affect judgement [8]. Each person has his/her own experience and custom, each culture has its own tradition and history. This kind of accumulation of memory can have influence on the evaluation of tropical architecture. Therefore, how to fit the architecture with personal custom or experience is also can be considered as the direction that the tropical residential building followed.

\section{REFERENCES}

[1] Duanfang Lu., Third World Modernism: Architecture, Development and Identity, Routledge: New York, pp. 224, 238, 2010.

[2] Robson, D., Vernacular Traditions and Modernity. Architecture and Urbanism: $A+U$, 6, pp. 19, 2008.

[3] Tang, G., The Climate of Five Ridges with Tradition Architecture, China Building Industry Press: Beijing, p. 28, 2007.

[4] Stagno, B., Architecture in Tropical Area. Architectural Journal, 29, pp. 1-6, 2001.

[5] Farfor, S., Andrew, D. \& Finlay, H., Northern Territory. Lonely Planet, Footscray, p. 103, 2003.

[6] Goad, P. \& Pieris, A., New Directions in Tropical Asian Architecture, Periplus: Singapore, p. 11, 2005.

[7] Robson, D., Tropical Ambassador. Architectural Record, 3, p. 65, 2009.

[8] Schutte, H. \& Ciarlante, D., Possible Obstacles in Environmental Design. Singapore Architecture, 3, p. 52, 2002. 